\title{
Prognostic phenotypic and genotypic factors associated with photodynamic therapy response in patients with age-related macular degeneration
}

This article was published in the following Dove Press journal:

Clinical Ophthalmology

5 December 2014

Number of times this article has been viewed

\author{
Takashi Tsuchihashi' \\ Keisuke Mori \\ Kuniko Horie-Inoue ${ }^{2}$ \\ Yasushi Okazaki ${ }^{3}$ \\ Takuya Awata ${ }^{4,5}$ \\ Satoshi Inoue ${ }^{2}$ \\ Shin Yoneya' \\ 'Department of Ophthalmology, \\ ${ }^{2}$ Division of Gene Regulation \\ and Signal Transduction, Research \\ Center for Genomic Medicine, \\ Johns Hopkins University School \\ of Medicine, Baltimore, MD, \\ USA; ${ }^{3}$ Division of Translational \\ Research, Research Center for \\ Genomic Medicine, ${ }^{4}$ Division \\ of Endocrinology and Diabetes, \\ Department of Medicine, ${ }^{5}$ Division \\ of RI Laboratory, Biomedical Research \\ Center, Saitama Medical University, \\ Iruma, Saitama, Japan
}

Background: This study aimed to demonstrate the phenotypic and genotypic factors associated with photodynamic therapy (PDT) for age-related macular degeneration (AMD).

Methods: The study included 149 patients with exudative AMD treated by PDT. Eight phenotypic factors and ten genotypic factors for three single nucleotide polymorphisms (SNPs; rs800292, rs1061170, rs1410996) in the complement factor $\mathrm{H}(\mathrm{CFH})$ gene, rs 11200638-SNP in the high temperature requirement A-1 (HTRA1) gene, two SNPs (rs699947, rs2010963) in the vascular endothelial growth factor (VEGF) gene, and four SNPs (rs12948385, rs12150053, rs9913583, rs1136287) in the pigment epithelium-derived factor (PEDF) gene were evaluated.

Results: A significant association with best-corrected visual acuity change was demonstrated in the greatest linear dimension, presence or absence of pigment epithelial detachment, and HTRA1-rs11200638 genotype statistically ( $P=3.67 \times 10^{-4}, 1.95 \times 10^{-2}, 1.24 \times 10^{-3}$, respectively). Best-corrected visual acuity in patients with AA genotype of HTRA1-rs11200638 significantly decreased compared with that in patients with GG genotype $\left(P=1.33 \times 10^{-3}\right)$. Logistic regression analyses demonstrated HTRA1-rs11200638 genotype was most strongly associated with best-corrected visual acuity outcome from baseline at 12 months after photodynamic therapy ( $P=4.60 \times 10^{-3}$; odds ratio $2.363 ; 95 \%$ confidence interval $\left.1.303-4.285\right)$.

Conclusion: The HTRA1-rs11200638 variant showed the most significant association. Therefore, this variant may be used as a prognostic factor to estimate the PDT response with significant predictive power.

Keywords: age-related macular degeneration, photodynamic therapy, phenotypic and genotypic factors, high temperature requirement A-1, greatest linear dimension, pigment epithelial detachment

\section{Introduction}

Age-related macular degeneration (AMD; [ARMD1 MIM603075]) is the leading cause of central vision loss in the elderly and is estimated to affect over 50 million people worldwide. ${ }^{1}$ It is a multifactorial disease with several identified genetic and environmental risk factors, including age, smoking, body mass index, hypertension, and others. ${ }^{2-5}$ Family-based genome-wide and candidate region linkage studies have successfully identified several major chromosomal regions, including $1 \mathrm{q} 31$ and $10 \mathrm{q} 26^{6-11}$

Photodynamic therapy (PDT) with verteporfin has been previously shown to be beneficial and safe as one of the standard therapies for subfoveal choroidal neovascularization $(\mathrm{CNV}) .{ }^{12-17}$ It has been reported that the effectiveness of PDT is influenced by various baseline composition factors, ${ }^{18,19}$ such as subtypes (typical AMD/polypoidal choroidal vasculopathy [PCV] $),{ }^{12-14,20-22} \mathrm{CNV}$ type classified using
Correspondence: Takashi Tsuchihashi Department of Ophthalmology, Saitama Medical University, 38 Morohongo, Moroyama, Iruma, Saitama,

350-0495, Japan

Tel +81492761250

Fax +8I492958002

Email tsuchi@saitama-med.ac.jp 
fluorescein angiography, ${ }^{17-19,23,24}$ the greatest linear dimension (GLD), ${ }^{17-19,25}$ the presence or absence of pigment epithelial detachment (PED), ${ }^{26,27}$ and best-corrected visual acuity (BCVA). ${ }^{17,18,24,28}$ Previous reports revealed that patients with PCV lesions, predominantly classic CNV, lesions with smaller GLD, lesions without PED, and patients with better BCVA showed better outcomes with PDT. Patients with AMD in Northeast Asia have been reported to have PCV lesions more frequently than Caucasian patients, ${ }^{29-32}$ PDT provides favorable outcomes in treating patients with PCV. ${ }^{20-22,33,34}$ Although anti-vascular endothelial growth factor therapies are currently the first-choice therapies for AMD patients, PDT is still one of the important therapies, especially for PCV patients.

AMD is a complex disease with multiple genetic and environmental factors. ${ }^{6-11}$ The complement factor $\mathrm{H}(\mathrm{CFH})$ gene on chromosome 1q31 has been demonstrated to be the major AMD susceptibility gene. ${ }^{35-41}$ Furthermore, genetic variants at another chromosomal locus, 10q26, confer a strong disease risk; these variants include age-related maculopathy susceptibility $2(A R M S 2)^{42-46}$ and high-temperature requirement factor A1 $(H T R A 1)^{47-49}$ genes. Several reports have been published about the association between genotype and PDT response in $C F H$ variants and HTRAl variants in various countries. ${ }^{50-54}$ However, the results of these reports differed ethnically, and the scientific significance of the association between the genetic variant and PDT outcomes remains controversial. In Japanese patients, we have reported the potential association between PDT response and HTRA1, $C F H$, vascular endothelial growth factor (VEGF), and pigment epithelium-derived factor $(P E D F)$ variants of AMD patients, as indicated by visual outcome, incidence of CNV recurrence, and postoperative adverse events. ${ }^{55}$ Moreover, we have described a significant association between HTRA1rs11200638 and $C F H$-rs 1410996 genotype variants and PDT response in AMD patients.

To the best of our knowledge, few reports were available on comparison of both phenotype and genotype with PDT response. ${ }^{56}$ Therefore, this raised an extremely important question regarding the significant factors, such as phenotypes, genotypes, and environmental factors influencing the response to PDT. Identifying the strongest influencing factor on PDT response and adequately estimating the prognosis of PDT before therapy may be helpful in determining precise personalized therapy for AMD patients. In this study, we compared the effect of each factor side-by-side with BCVA outcomes at 12 months after PDT.

\section{Materials and methods}

\section{Study subjects}

The present study was designed as a prospective case-control study and included 149 patients with newly-diagnosed exudative AMD who had received unilateral PDT. The participants comprised 112 males and 37 females of mean age $71.1 \pm 8.3$ (range 50-91) years. Baseline demographics are presented in Table 1. All patients were recruited from outpatients visiting the Department of Ophthalmology, Saitama Medical University Hospital, Saitama Prefecture, Japan. The study was approved by the ethics committee of Saitama Medical University (approved on December 9, 2003; approval number 03-262), and the procedures were conducted in accordance with the principles of the Declaration of Helsinki. A thorough explanation was given to each participant regarding the purpose and procedures involved in the study. Informed written consent was obtained from each patient before treatment.

\section{Ophthalmic examination, definition, and classification of AMD}

All patients were examined using BCVA, fundus photography, fluorescein and indocyanine green angiography, and optical

Table I Baseline characteristics of patients with AMD

\begin{tabular}{ll}
\hline Charactaristics & Value \\
\hline Patients $(n)$ & $149 *$ \\
Age, years (mean \pm SD) & $71.8 \pm 8.3$ \\
Age distribution, years & \\
$50-59$ & $17(11.4)^{*}$ \\
$60-69$ & $43(28.9)^{*}$ \\
$70-79$ & $65(43.6)^{*}$ \\
$80-89$ & $21(14.1)^{*}$ \\
$>90$ & $3(2.0)$ \\
Sex (male/female) & $112 / 37^{*}$ \\
Subtypes & \\
Typical AMD & $85(57.0)^{*}$ \\
PCV & $64(43.0)^{*}$ \\
Fluorescein angiographic classification & \\
Predominantly classic CNV & $38(25.5)^{*}$ \\
Minimally classic CNV & $46(30.9)^{*}$ \\
Occult with no classic CNV & $65(43.6)^{*}$ \\
Greatest linear dimension of lesion, $\mu m$ (mean $\pm S D)$ & $2,966 \pm 1,305$ \\
Central retinal thickness, $\mu m$ (mean \pm SD) & $495 \pm 167$ \\
Pigment epithelium detachment (presence/absence) & $36 / 113^{*}$ \\
LogMAR vision (mean \pm SD) & $0.578 \pm 0.413$ \\
Mean BCVA (approximate Snellen equivalent) & $20 / 80$ \\
\hline
\end{tabular}

Notes: *Value represents the number of patients (\% of the entire group), except for age, greatest linear dimension of lesion, central retinal thickness, logMAR vision, and mean BCVA.

Abbreviations: AMD, age-related macular degeneration; CNV, choroidal neovascularization; BCVA, best-corrected visual acuity; logMAR, logarithm of minimum angular resolution; PCV, polypoidal choroidal vasculopathy; SD, standard deviation. 
coherence tomography (Stratus OCT; Carl Zeiss Meditec AG, Jena, Germany). The inclusion criteria were as follows: age $\geq 50$ years, diagnosis of exudative AMD in one or both eyes, and no association with other retinochoroidal diseases such as angioid streaks, high myopia (greater than six diopters of myopic refractive error), central serous chorioretinopathy, and presumed ocular histoplasmosis. BCVA was measured at initial presentation and 12 months after PDT. For the calculations and comparisons, BCVA measurements were converted to logarithm of minimum angular resolution $(\log$ MAR) values.

We selected the eight phenotypes (clinical findings and environmental factors): age, sex, subtypes (typical AMD versus PCV), CNV types (classic CNV versus occult CNV), GLD, pre-PDT BCVA, pre-PDT central retinal thickness measured using spectral OCT Stratus 4 software (Carl Zeiss Meditec AG), and the presence or absence of PED. All cases were divided into two subtypes, ie, typical AMD (85 eyes, $57 \%$ ) and PCV (64 eyes, 43\%). The differential diagnosis of typical AMD or PCV depended on the presence or absence of the polypoidal structure of choroidal vessels and any abnormal vascular networks using indocyanine green angiography. CNV types were subcategorized on the basis of the classification described in the Treatment of Age-Related Macular Degeneration with Photodynamic Therapy (TAP) study. ${ }^{15}$ Lesions were classified into classic CNV (84 eyes, 56\%; predominantly and minimally classic CNV) and occult CNV (65 eyes, $44 \%$; occult with no classic $\mathrm{CNV}$ ). Central retinal thickness was measured at the foveola (between the retinal inner surface and retinal pigment epithelium) by OCT at baseline. The presence of PED was determined by the existence of PED larger than two disc areas including the foveal region.

All funduscopic, angiographic, and OCT data were evaluated by three retina specialists (TT, KM, and SY). These examiners did not agree on the status of five patients, so a reviewer $(\mathrm{KM})$ determined the diagnosis, recurrence, and complications. All examiners were masked for the genotyping results when examining the clinical data.

\section{Therapeutic procedures}

The therapy protocol followed that used in the Japanese Age-Related Macular Degeneration Trial (JAT) study, ${ }^{17}$ ie, a 10 -minute intravenous infusion of verteporfin $\left(6 \mathrm{mg} / \mathrm{m}^{2}\right.$ body surface area) followed by a 15-minute light exposure after introduction of the infusion. Light exposure was provided with a diode laser beam $(639 \pm 3 \mathrm{~nm})$ at $600 \mathrm{~mW} / \mathrm{cm}^{2}$ for 83 seconds to produce $50 \mathrm{~J} / \mathrm{cm}^{2}$.

\section{Genotyping and statistical analyses}

Genomic DNA was extracted from the peripheral blood of each individual using a DNA extraction and purification kit (Wizard Genomic DNA Purification Kit; Promega, Madison, WI, USA) according to the manufacturer's instructions. The samples were genotyped (TaqMan genotyping assay with the ABI Prism 7000 sequence detection system; Applied Biosystems Inc, Foster City, CA, USA), and the data were analyzed (Allelic Discrimination Program). Two single nucleotide polymorphisms (SNPs, rs 2010963 and rs699947) in the VEGF gene, four SNPs (rs12948385, rs12150053, rs9913583, rs1136287) in the PEDF gene, three SNPs (rs1061170, rs800292, rs1410996) in the $C F H$ gene, and one SNP (rs11200638) in the HTRA1 gene were assessed.

We analyzed whether the BCVA changes from baseline were associated with phenotypes and genotypes using the unpaired $t$-test (for sex, subtypes, CNV type, and PED) between two groups, one-way analysis of variance, and Bonferroni multiple comparison correction among three groups for all genotypes, and single regression analysis (for age, GLD, pre-PDT BCVA, and pre-PDT central retinal thickness) for quantitative variables. Two methods of analysis were performed to examine the factors influencing change in BCVA. Stepwise multiple regression analysis was performed to evaluate the various factors that might be useful for predicting BCVA change. To identify factors independently associated with BCVA change, five potential risk factors that were significant at $P<0.2$ were included in a forward logistic regression model. The associations between the phenotypes/genotypes and outcomes of BCVA were evaluated by logistic regression analysis for estimation of the odds ratio and corresponding 95\% confidence interval $(0$, worsened [ $>0.3 \log$ MAR BCVA] and 1, maintained [ $\pm 0.3 \log$ MAR BCVA] or improved [ $>0.3 \log$ MAR BCVA] change from baseline). $P<0.05$ was prospectively considered to be statistically significant. All analyses except those that calculated joint effects were performed using commercially available software (SNPAlyze version 6.0.1; Dynacom, Chiba, Japan: SSRI version 1.20; SSRI, Tokyo, Japan).

\section{Results}

Of 149 patients with AMD, 85 (57\%) were diagnosed with typical AMD and 64 (43\%) were diagnosed with PCV. Eightyfour patients (56\%) had classic CNV and 65 (44\%) had occult lesions without classic CNV (Table 1). The number of PDT treatments ranged from one to four (mean 2.1 \pm 0.69 ) during the 12-month period. Baseline and post-treatment BCVA for all 
eyes were assessed in this study for an association with $V E G F$ rs2010963 and -rs699947, PEDF-12948385, -12150053, -9913583, and -1136287, CFH-rs1061170, -rs1410996, and -rs800292, and HTRA1-rs11200638 genotypes. Table 2 reveals the change in BCVA from baseline based on the phenotypes and genotypes tested at 12 months after PDT. BCVA changes with GLD, the presence or absence of PED, and HTRA1-rs1 1200638 showed significant association with BCVA outcome and differences $\left(P=3.67 \times 10^{-4}, 1.95 \times 10^{-2}, 1.24 \times 10^{-3}\right.$, respectively). Moreover, the change in BCVA between patients with the risk allele homozygous genotype (AA) and wild-type homozygous genotype (GG) of HTRA1-rs1 1200638 showed significant differences ( $P=1.33 \times 10^{-3}$; Bonferroni correction).

Stepwise regression analysis revealed that GLD (beta $0.221, P=0.012$ ), PED (beta 0.183, $P=0.039$ ), and HTRA1rs11200638 (beta $0.253, P=5.29 \times 10^{-3}$ ) were independently associated with BCVA change at 12 months after PDT, which was better in patients with smaller GLD, without PED, or GG type (Table 3). HTRA1 showed the strongest association with BCVA change. The correlation coefficient $\left(R^{2}\right)$ was calculated as 0.235 .
Table 4 shows the $P$-values and odds ratios that were analyzed by logistic regression for the outcomes of PDT (0, worsened BCVA and 1, maintained or improved BCVA) in five prognostic factors (GLD, PED, $P E D F$-rs12948385, -rs12150053, and HTRA1). Among the two tested phenotypes and three tested genotypes, significant associations with BCVA outcomes were demonstrated with GLD and HTRA1-rs11200638 genotype $(P=0.0197$, odds ratio 1.004 , $95 \%$ confidence interval $1.001-1.007 ; P=4.60 \times 10^{-3}$, odds ratio $2.363,95 \%$ confidence interval $1.303-4.285$, respectively). HTRA1 showed the greatest association among the five prognostic factors.

\section{Discussion}

In the present study, we identified significant differences according to the presence or absence of PED and HTRA1rs11200638 genotype as well as a significant association between GLD and BCVA change at 12 months (therapeutic response to PDT) in AMD patients. Our data demonstrate that the patients with smaller GLD, without PED, and with GG genotype HTRA1-rs11200638 had significantly better

Table 2 Best-corrected visual acuity changes from baseline at 12 months after photodynamic therapy

\begin{tabular}{|c|c|c|c|}
\hline Factors & BCVA change & $R$ & $P$-value \\
\hline \multicolumn{4}{|l|}{ Phenotypes } \\
\hline Age & NA & 0.051 & 0.530 \\
\hline Sex (male/female) & $0.046 \pm 0.385 / 0.047 \pm 0.403$ & - & 0.983 \\
\hline Subtypes (typical AMD/PCV) & $0.047 \pm 0.315 / 0.045 \pm 0.472$ & - & 0.980 \\
\hline CNV type (classic/occult) & $0.069 \pm 0.354 / 0.037 \pm 0.402$ & - & 0.649 \\
\hline GLD & NA & 0.297 & $3.67 \times 10^{-4 t}$ \\
\hline Pre-PDT BCVA & NA & 0.071 & 0.384 \\
\hline Pre-PDT CRT & NA & 0.046 & 0.596 \\
\hline PED (presence/absence) & $0.183 \pm 0.501 / 0.008 \pm 0.337$ & - & $1.95 \times 10^{-2 \dagger}$ \\
\hline \multicolumn{4}{|l|}{ Genotypes } \\
\hline \multicolumn{4}{|l|}{ VEGF } \\
\hline rs2010963 & $-0.014(35) / 0.036(80) / 0.128(34)$ & - & 0.308 \\
\hline rs699947 & $0.07 \mid(82) /-0.018(60) /-0.007(7)$ & - & 0.696 \\
\hline \multicolumn{4}{|l|}{ PEDF } \\
\hline rs 12948385 & $0.339(3) / 0.050(43) / 0.037(103)$ & - & 0.419 \\
\hline rs 12150053 & $0.329(4) / 0.065(40) / 0.034(105)$ & - & 0.320 \\
\hline rs9913583 & $0.407(3) / 0.025(37) / 0.044(109)$ & - & 0.261 \\
\hline rsII36287 & $0.017(43) / 0.038(67) / 0.080(39)$ & - & 0.783 \\
\hline \multicolumn{4}{|l|}{$\mathrm{CFH}$} \\
\hline rs1061170 & $0.046(128) / 0.036(2 I) / \mathrm{NA}(0)$ & - & 0.911 \\
\hline rs800292 & $0.222(13) /-0.015(6 \mathrm{I}) / 0.066(75)$ & - & 0.131 \\
\hline rs|4I0996 & $0.122(13) / 0.023(78) / 0.058(58)$ & - & 0.678 \\
\hline \multicolumn{4}{|l|}{ HTRAI } \\
\hline rsII 200638 & $-0.150(24) / 0.014(79) / 0.201(46)$ & - & $1.24 \times 10^{-3+}$ \\
\hline
\end{tabular}

Notes: Data in phenotype columns are expressed as the mean BCVA change from baseline $(\mathrm{n})$ for each phenotype and genotype (non-risk allele homozygous/heterozygous/ risk allele homozygous, respectively), correlation coefficient ( $r$ ) and $P$-values; 'statistically significant.

Abbreviations: CFH, complement factor H; HTRA I, high temperature requirement A- I; NA, not available; PEDF, pigment epithelium-derived factor; VEGF, vascular endothelial growth factor; PED, pigment epithelium detachment; GLD, greatest linear dimension; PDT, photodynamic therapy; CRT, central retinal thickness; AMD, age-related macular degeneration; PCV, polypoidal choroidal vasculopathy; CNV, choroidal neovascularization; BCVA, best-corrected visual acuity. 
Table 3 Prognostic factors for change in BCVA including phenotypes and genotypes

\begin{tabular}{|c|c|c|c|}
\hline & CR & Beta & $P$-value \\
\hline \multicolumn{4}{|l|}{ Phenotypes } \\
\hline Age & 0.002 & 0.065 & 0.442 \\
\hline Sex (male/female) & 0.014 & 0.015 & 0.847 \\
\hline Subtypes (typical AMD/PCV) & -0.011 & -0.015 & 0.875 \\
\hline CNV type (classic/occult) & 0.037 & 0.043 & 0.631 \\
\hline GLD & $6.62 \times 10^{-5}$ & 0.221 & $0.012^{\dagger}$ \\
\hline Pre-PDT BCVA & -0.001 & -0.029 & 0.730 \\
\hline Pre-PDT CRT & $9.37 \times 10^{-6}$ & 0.004 & 0.959 \\
\hline PED (presence/absence) & 0.167 & 0.183 & $0.039+$ \\
\hline \multicolumn{4}{|l|}{ Genotypes } \\
\hline \multicolumn{4}{|l|}{ VEGF } \\
\hline rs2010963 & -0.041 & -0.073 & 0.393 \\
\hline rs699947 & -0.018 & -0.027 & 0.753 \\
\hline \multicolumn{4}{|l|}{ PEDF } \\
\hline rs 12948385 & -0.334 & $-0.44 I$ & 0.140 \\
\hline rs 12150053 & 0.380 & 0.112 & 0.091 \\
\hline rs9913583 & -0.048 & -0.062 & 0.519 \\
\hline rsII36287 & -0.003 & -0.007 & $0.94 I$ \\
\hline \multicolumn{4}{|l|}{ CFH } \\
\hline rs 1061170 & -0.011 & -0.010 & 0.907 \\
\hline rs800292 & 0.054 & 0.087 & 0.457 \\
\hline rs|410996 & -0.020 & -0.034 & 0.762 \\
\hline \multicolumn{4}{|l|}{ HTRAI } \\
\hline rsII200638 & 0.146 & 0.253 & $5.29 \times 10^{-3 \dagger}$ \\
\hline
\end{tabular}

Notes: Correlation coefficient squared $\left(R^{2}\right)=0.235$; ${ }^{\dagger}$ significant by stepwise multiple regression analyses.

Abbreviations: AMD, age-related macular degeneration; CR, coefficient of regression; Beta, standardized partial regression coefficient; PED, pigment epithelium detachment; GLD, greatest linear dimension; PDT, photodynamic therapy; CRT, central retinal thickness; BCVA, best-corrected visual acuity; CNV, choroida neovascularization; PCV, polypoidal choroidal vasculopathy; CFH, complement factor $\mathrm{H}$; HTRAI, high temperature requirement A-I; PEDF, pigment epitheliumderived factor; VEGF, vascular endothelial growth factor.

outcomes after receiving PDT. Using stepwise regression and logistic regression analysis, the HTRA1-rs11200638 gene was found to have the strongest significant association with the outcomes of PDT among all tested phenotypic and genotypic factors. However, the subtypes were not associated with the outcomes of PDT for all analyses.

Table $4 P$-values and odds ratios for BCVA outcomes after PDT

\begin{tabular}{lll}
\hline Factors & $P$-value & OR $(95 \% \mathrm{Cl})$ \\
\hline GLD & $0.0197^{\dagger}$ & $1.004(1.001-1.007)$ \\
PED & 0.8654 & $0.925(0.377-2.267)$ \\
PEDF & & \\
rs I2948385 & 0.5573 & $0.450(0.031-6.479)$ \\
rsI2I50053 & 0.4105 & $2.974(0.221-39.9 I)$ \\
HTRAI & & \\
$\quad$ rsII200638 & $4.60 \times 10^{-3 \dagger}$ & $2.363(1.303-4.285)$
\end{tabular}

Notes: †Statistically significant. Data in probabilities and odds ratios are calculated by logistic regression analysis.

Abbreviations: PED, pigment epithelium detachment; GLD, greatest linear dimension; PDT, photodynamic therapy; BCVA, best-corrected visual acuity; $\mathrm{Cl}$, confidence interval; OR, odds ratio; HTRAI, high temperature requirement $\mathrm{A}-\mathrm{I}$; $P E D F$, pigment epithelium-derived factor.
Previous studies (TAP and Visudyne in Photodynamic Therapy [VIP]) in larger populations have reported that the effects of PDT with verteporfin for AMD varied according to the baseline lesion composition. ${ }^{18,19}$ TAP and the first VIP report showed that lesion size was an important predictor of the magnitude on verteporfin therapeutic benefit in both occult with no classic and minimally classic lesion composition. ${ }^{19}$ Furthermore, Arias et $\mathrm{a}^{25}$ similarly concluded that lesion size at baseline may be a prognostic factor for PDT in patients with subfoveal predominantly classic CNV secondary to AMD. Many patients with larger GLD showed a poor response to PDT irrespective of the classification of CNV type in the aforementioned reports. This poorer response may be due to the occurrence of smaller GLDs at the early stages of disease, and patients who had larger GLDs may have had greater disease activity and progression of CNV. Similarly, our data showed that GLD had a significant association with the outcomes of PDT. Like previous reports, these results suggest that GLD is one of the important factors in predicting the prognosis of PDT in the Japanese population.

In addition, PED demonstrated a significant difference and an association with phenotypes in the present study. AMD patients with PED had significantly worse results than those without PED. The outcomes for patients with PED lesions have been extremely poor, either through their natural history or after receiving laser therapy. ${ }^{57-59}$ The appearance of PED as a complication of AMD is an adverse prognostic factor commonly associated with severe visual dysfunction. However, previous important pilot and randomized studies (TAP and VIP studies) have not adequately focused on PED. ${ }^{16}$ Several studies have reported that the effects of PDT depend on the presence of PED..$^{26,27}$ Axer-Siegel et al ${ }^{26}$ reported poor results after PDT for CNV with PED and that eyes with PED occupying more than $50 \%$ of the lesion were ineligible for this therapy because of an increased rate of visual and anatomic complications after PDT. Pece et $\mathrm{al}^{27}$ found that PDT can improve or stabilize visual function in $60 \%$ of eyes with vascularized PED and that a CNV at the edge of PED appears to respond more favorably to PDT. However, we cannot completely evaluate whether our data presented an accurate comparison with these previous reports because the definition of PED such as size, height, PED composition, and location (we defined the presence of PED as a lesion with 2 disc area more over in size including fovea) differed among the various studies. However, considering the results of previous reports and those of our study, we estimate that the results of PDT in patients with PED were worse when compared with results in patients without PED, 
because the laser light could be absorbed by subretinal fluid under the PED and might not penetrate CNV. The findings of the present study indicate that PDT has questionable benefit in AMD eyes with PED.

In contrast, PDT has been reported to be a good therapeutic modality in patients with PCV.${ }^{12-14}$ However, PDT for PCV often has to be repeated, either because of persistent disease or recurrence. The phenotypic and genotypic characteristics of AMD in the Asian and Japanese populations are different from those of AMD in the Caucasian population. ${ }^{32}$

Regarding phenotype, the incidence of PCV in the Asian population with neovascular AMD has been reported to be higher than that in the Caucasian population. ${ }^{29,31,32,60-65}$ Moreover, PDT has been reported to be a good therapeutic modality for PCV, so is important in treating Asian and Caucasian patients with AMD. ${ }^{12-14}$ The different response to PDT is more evident when the TAP ${ }^{15}$ and VIP ${ }^{16}$ reports are compared with the better PDT response reported in the JAT study population. ${ }^{17}$ However, a significant association between disease subtype and PDT response was not observed in our study. We assume that other phenotypic factors, such as PED and GLD, might be more statistically influential on PDT outcomes rather than disease subtype. Further studies with increased case numbers will be required to assess this issue by considering the treatment frequency of PDT.

Regarding genotype, various genes have been identified as the major AMD susceptibility gene, and research in the area of genetic associations in AMD has expanded exponentially. ${ }^{35-49}$ Therefore, progress in this emerging field has been now acknowledged and significantly increased our understanding of the susceptibility to and pathogenesis of AMD disease.

Other efforts are in progress to identify genetic and/ or pharmacological biomarkers that may predict response to therapy, thereby contributing important information to clinical decision-making and in providing appropriate care. Recently, a genetic variant of $\mathrm{CFH} Y 402 \mathrm{H}$ was reported to be associated with the response to PDT and to anti-VEGF therapy in a Caucasian population that included residents of the UK and USA. ${ }^{50-52}$ However, Seitsonen et $\mathrm{al}^{53}$ reported that CFH Y402H polymorphism did not show a significant association with PDT response in Caucasian residents in Finland. Chowers et $\mathrm{al}^{54}$ found no significant association between PDT response and ARMS2/HTRA1 polymorphisms in the Arab, Sephardic Jewish, and Ashkenazi Jewish populations of Israel. Moreover, we have reported a significant relationship between HTRA 1 and $C F H$ genes and the PDT response in the Japanese population. ${ }^{55}$ We have included more patients in the present study than in our previous study, and a stronger association was similarly observed with the HTRA1 gene. These results support the hypothesis that known genetic polymorphisms (particularly HTRA1-rs11200638) may be utilized as genetic biomarkers to predict PDT responses in Japanese AMD patients. Furthermore, HTRA1-rs11200638 was the major influence on outcomes of PDT in the tested genotypes and the clinical phenotypes in current study.

Further steps in this emerging area are to explore additional novel genetic biomarkers that predict the efficacy and safety of PDT and more investigation of the association with anti-VEGF therapy ${ }^{66-68}$ in the Asian population afflicted with AMD. If genetic differences between PDT and anti-VEGF therapy are found, we might be able to determine the most appropriate therapy (as personalized medicine) by analyzing the genotypes of such new biomarkers. Further, it remains to be more characterized the functions of known genes associated with AMD to predict precisely the efficacy of PDT and anti-VEGF therapy. ${ }^{66-68}$ So far we conclude that HTRA1 is a more important factor than other phenotypic factors in predicting the response to PDT.

\section{Acknowledgments}

This research was supported in part by a Grant from the Eye Research Foundation for the Aged (to KM), an institutional grant from the Medical Research Center, Saitama Medical University (to KM) and a grant-in-aid for scientific research (21592242) from the Ministry of Education, Culture and Science in Japan (to KM).

\section{Disclosure}

The authors report no conflicts of interest in this work.

\section{References}

1. Klein R, Peto T, Bird A, Vannewkirk MR. The epidemiology of age-related macular degeneration. Am J Ophthalmol. 2004;137: 486-495.

2. Age-Related Eye Disease Study Research Group. Risk factors for the incidence of advanced age-related macular degeneration in the AgeRelated Eye Disease Study: AREDS report no. 19. Ophthalmology. 2005; 112:533-539.

3. Kaiserman I, Kaiserman N, Elhayany A, Vinker S. Risk factors for photodynamic therapy of predominantly classic choroidal neovascularization in age-related macular degeneration. Am J Ophthalmol. 2006;142:441-447.

4. Choudhury F, Varma R, McKean-Cowdin R, Klein R, Azen SP; Los Angeles Latino Eye Study Group. Risk factors for four-year incidence and progression of age-related macular degeneration: the Los Angeles Latino eye study. Am J Ophthalmol. 2011;152:385-395.

5. Kabasawa S, Mori K, Horie-Inoue K, et al. Association of cigarette smoking but not serum fatty acids with age-related macular degeneration in a Japanese population. Ophthalmology. 2011;118:1082-1088.

6. Klein ML, Schultz DW, Edwards A, et al. Age-related macular degeneration. Clinical features in a large family and linkage to chromosome 1q. Arch Ophthalmol. 1998;116:1082-1088. 
7. Weeks DE, Conley YP, Mah TS, et al. A full genome scan for agerelated maculopathy. Hum Mol Genet. 2000;9:1329-1349.

8. Majewski J, Schultz DW, Weleber RG, et al. Age-related macular degeneration- a genome scan in extended families. Am J Hum Genet. 2003;73:540-550.

9. Seddon JM, Santangelo SL, Book K, Chong S, Cote J. A genomewide scan for age-related macular degeneration provides evidence for linkage to several chromosomal regions. Am J Hum Genet. 2003;73:780-790.

10. Abecasis GR, Yashar BM, Zhao Y, et al. Age-related macular degeneration: a high-resolution genome scan for susceptibility loci in a population enriched for late-stage disease. Am J Hum Genet. 2004;74:482-494.

11. Fisher SA, Abecasis GR, Yashar BM, et al. Meta analysis of genome scans of age-related macular degeneration. Hum Mol Genet. 2005; 14:2257-2264.

12. Gomi F, Ohji M, Sayanagi K, et al. One-year outcomes of photodynamic therapy in age-related macular degeneration and polypoida choroidal vasculopathy in Japanese patients. Ophthalmology. 2008;115: 141-146.

13. Chan WM, Lai TY, Tano Y, Liu DT, Li KK, Lam DS. Photodynamic therapy in macular diseases of Asian populations: when East meets West. Jpn J Ophthalmol. 2006;50:161-169.

14. Cho M, Barbazetto IA, Freund B. Refractory neovascular age-related macular degeneration secondary to polypoidal choroidal vasculopathy. Am J Ophthalmol. 2009;148:70-78.

15. Bresler NM; Treatment of Age-Related Macular Degeneration with Photodynamic Therapy (TAP) Study Group. Photodynamic therapy of subfoveal choroidal neovascularization in age-related macular degeneration with verteporfin: two-year results of 2 randomized clinical trials- TAP report 2. Arch Ophthalmol. 2001;119:198-207.

16. Verteporfin In Photodynamic Therapy Study Group. Verteporfin therapy of subfoveal choroidal neovascularization in age-related macular degeneration: two-year results of a randomized clinical trial including lesions with occult with no classic choroidal neovascularization-verteporfin in photodynamic therapy report 2. Am J Ophthalmol. 2001;131: $541-560$

17. Japanese Age-Related Macular Degeneration Trial (JAT) Study Group. Japanese age-related macular degeneration trial: 1-year results of photodynamic therapy with verteporfin in Japanese patients with subfoveal choroidal neovascularization secondary to age-related macular degeneration. Am J Ophthalmol. 2003;136:1049-1061.

18. Treatment of Age-Related Macular Degeneration with Photodynamic Therapy (TAP) Study Group. Verteporfin therapy of subfoveal choroidal neovascularization in patients with age-related macular degeneration: additional information regarding baseline lesion compositions impact on vision outcomes- TAP report no. 3. Arch Ophthalmol. 2002; 120:1443-1454.

19. Blinder KJ, Bradley S, Bressler NM, et al. Treatment of Age-Related Macular Degeneration with Photodynamic Therapy Study Group. Verteporfin in Photodynamic Therapy Study Group: effect of lesion size, visual acuity, and lesion composition on visual acuity change with and without verteporfin therapy for choroidal neovascularization secondary to age-related macular degeneration: TAP and VIP report no. 1. Am J Ophthalmol. 2003;136:407-418.

20. Chan WM, Lam DS, Lai TY, et al. Photodynamic therapy with verteporfin for symptomatic polypoidal choroidal vasculopathy: one-year results of a prospective case series. Ophthalmology. 2004;111:1576-1584.

21. Quaranta M, Maugot-Faysse M, Coscas G. Exudative idiopathic polypoidal choroidal vasculopathy and photodynamic therapy with verteporfin. Am J Ophthalmol. 2002;134:277-280.

22. Spaide RF, Donsoff I, Lam DL, et al. Treatment of polypoidal choroidal vasculopathy with photodynamic therapy. Retina. 2002;22:529-535.

23. [No authors listed]. Photodynamic therapy of subfoveal choroidal neovascularization in age-related macular degeneration with verteporfin: one-year results of 2 randomized clinical trials - TAP report. Treatment of Age-Related Macular Degeneration with Photodynamic Therapy (TAP) Study Group. Arch Ophthalmol. 1999;117:1329-1345.
24. Verteporfin in Photodynamic Therapy Study Group. Verteporfin therapy of subfoveal choroidal neovascularization in age-related macular degeneration: two-year results of a randomized clinical trial including lesions with occult with no classic choroidal neovascularization-verteporfin in photodynamic therapy report 2. Am J Ophthalmol. 2001;131:541-560.

25. Arias L, Pujol O, Berniell J, et al. Impact of lesion size on photodynamic therapy with verteporfin of predominantly classic lesions in age related macular degeneration. Br J Ophthalmol. 2005;89:312-315.

26. Axer-Siegel R, Ehrlich R, Rosenblatt I, et al. Photodynamic therapy for occult choroidal neovascularization with pigment epithelium detachment in age-related macular degeneration. Arch Ophthalmol. 2004;122:453-459.

27. Pece A, Isola V, Vadala M, Calori G. Photodynamic therapy with verteporfin for choroidal neovascularization associated with retinal pigment epithelial detachment in age-related macular degeneration. Retina. 2007;27:342-348.

28. Honda S, Imai H, Yamashiro K, et al. Comparative assessment of photodynamic therapy for typical age-related macular degeneration and polypoidal choroidal vasculopathy: a multicenter study in Hyogo Prefecture, Japan. Br J Ophthalmol. 2005;89:312-315.

29. Sho K, Takahashi K, Yamada H, et al. Polypoidal choroidal vasculopathy: incidence, demographic features, and clinical characteristics. Arch Ophthalmol. 2003;121:1392-1396.

30. Yuzawa M, Mori R, Kawamura A. The origins of polypoidal choroidal vasculopathy. Br J Ophthalmol. 2005;89:602-607.

31. Maruko I, Iida T, Saito M, Nagayama D, Saito K. Clinical characteristics of exudative age-related macular degeneration in Japanese patients. Am J Ophthalmol. 2007;144:15-22.

32. Mori K, Horie-Inoue K, Gehlbach PL, et al. Phenotype and genotype characteristics of age-related macular degeneration in a Japanese population. Ophthalmology. 2010;117:928-938.

33. Lee SC, Seong YS, Kim SS, Koh HJ, Kwon OH. Photodynamic therapy with verteporfin for polypoidal choroidal vasculopathy of the macula. Ophthalmologica. 2004;218:193-201.

34. Silva RM, Figueira J, Cachulo ML, Duarte L, Faria de Abreu JR, Cunha-Vaz JG. Polypoidal choroidal vasculopathy and photodynamic therapy with verteporfin. Graefes Arch Clin Exp Ophthalmol. 2005; 243:973-979.

35. Klein RJ, Zeiss C, Chew EY, et al. Complement factor $\mathrm{H}$ polymorphism in age-related macular degeneration. Science. 2005;308:385-389.

36. Hainnes JL, Hauser MA, Schmidt S, et al. Complement factor $\mathrm{H}$ variant increases the risk of age-related macular degeneration. Science. 2005;308:419-421.

37. Edward AO, Ritter R 3rd, Abel KJ, Manning A, Panhuysen C, Farrer LA. Complement factor $\mathrm{H}$ polymorphism and age-related macular degeneration. Science. 2005;314:989-992.

38. Hageman GS, Anderson DH, Johnson LV, et al. A common haplotype in the complement regulatory gene factor $\mathrm{H}(\mathrm{HF} 1 / \mathrm{CFH})$ predisposes individuals to age-related macular degeneration. Proc Natl Acad Sci US A. 2005;102:7227-7232.

39. Li M, Atmaca-Sonmez P, Othman M, et al. CFH haplotypes without the $\mathrm{Y} 402 \mathrm{H}$ cording variant show strong association with susceptibility to age-related macular degeneration. Nat Genet. 2006;38:1049-1054.

40. Maller J, George S, Purcell S, et al. Common variation in three genes, including a noncording variant in $\mathrm{CFH}$, strongly influences risk of age-related macular degeneration. Nat Genet. 2006;38:1055-1059.

41. Mori K, Gehlbach PL, Kabasawa S, et al. Coding and noncoding variants in the $\mathrm{CFH}$ gene and cigarette smoking influence the risk of age-related macular degeneration. Invest Ophthalmol Vis Sci. 2007;48: 5315-5319.

42. Jackobsdottir J, Conley YP, Weeks DE, Mah TS, Ferrell RE, Gorin MB. Susceptibility genes for age-related maculopathy on chromosome 10q26. Am J Hum Genet. 2005;77:389-407.

43. Rivera A, Fisher SA, Fritsche LG, et al. Hypothetical LOC387715 is a second major susceptibility gene for age-related macular degeneration, contributing independently of complement factor $\mathrm{H}$ to disease risk. Hum Mol Genet. 2005;14:3227-3236. 
44. Schmidt S, Hauser MA, Scott WK, et al. Cigarette smoking strongly modifies the association of LOC387715 and age-related macular degeneration. Am J Hum Genet. 2006;78:852-864.

45. Fritsche LG, Loenhardt T, Janssen A, et al. Age-related macular degeneration is associated with an unstable ARMS2 (LOC387715) mRNA. Nat Genet. 2008;40:892-896.

46. Kanda A, Chen W, Othman M, et al. A variant of mitochondrial protein LOC387715/ARMS2, not HTRA1, is strongly associated with age-related macular degeneration. Proc Natl Acad Sci U S A. 2007; 104:16227-16232.

47. DeWan A, Liu M, Hartman S, et al. HTRA1 promoter polymorphism in wet age-related macular degeneration. Science. 2006;314:989-992.

48. Yang Z, Camp NJ, Sun H, et al. A variant of the HTRA1 gene increases susceptibility to age-related macular degeneration. Science. 2006;314:992-993.

49. Mori K, Horie-Inoue K, Kohda M, et al. Association of the HTRA1 gene variant with age-related macular degeneration in the Japanese population. J Hum Genet. 2007;52:634-641.

50. Goverdhan SV, Hannsen S, Newsom RB, Luff AJ, Griffiths H, Lotery AJ. An analysis of the CFH Y402H genotype in AMD patients and control from the UK, and response to PDT treatment. Eye (Lond). 2007;22:849-854.

51. Brantley MA Jr, Fang AM, King JM, Tewari A, Kymes SM, Shiels A. Association of complement factor $\mathrm{H}$ and LOC387715 genotypes with response of exudative age-related macular degeneration to intravitreal bevacizumab. Ophthalmology. 2007;114:2168-2173.

52. Brantley MA, Edelstein SL, King JM, et al. Association of complement factor $\mathrm{H}$ and LOC387715 genotypes with response of exudative agerelated macular degeneration to photodynamic therapy. Eye (Lond). 2008;23:626-631.

53. Seitsonen SP, Javela IE, Meri S, Tommila PV, Ranta PH, Immonen IJ. The effect of complement factor $\mathrm{H}$ Y $402 \mathrm{H}$ polymorphism on the outcome of photodynamic therapy in age-related macular degeneration. Eur J Ophthalmol. 2007;17:943-949.

54. Chowers I, Meir T, Lederman M, et al. Sequence variants in HTRA1 and LOC 387715/ARMS2 and phenotype and response to photodynamic therapy in neovascular age-related macular degeneration in populations from Israel. Mol Vis. 2008;14:2263-2271.

55. Tsuchihashi T, Mori K, Horie-Inoue K, et al. Complement factor $\mathrm{H}$ and high-temperature requirement A-1 genotypes and treatment response of age-related macular degeneration. Ophthalmology. 2011; 118:93-100.

56. Nakata I, Yamashiro K, Yamada R, et al. Genetic variants in pigment epithelium-derived factor influence response of polypoidal choroidal vasculopathy to photodynamic therapy. Ophthalmology. 2011;118: 1408-1415.

57. Elman MJ, Fine SL, Murphy RP, Patz A, Auer C. The natural history of serous retinal pigment epithelial detachments in patients with agerelated macular degeneration. Ophthalmology. 1986;93:224-230.
58. Maguire JI, Benson WE, Brown GC. Treatment of foveal pigment epithelial detachments with contiguous extrafoveal choroidal neovascular membranes. Am J Ophthalmol. 1990;109:523-529.

59. Brancato R, Introini U, Bolognesi G, Pacelli G, Trabucchi G, Pece A. Indocyanine green angiography-guided laser photocoagulation of occult choroidal neovascularization in age-related macular degeneration. Retina. 2000;20:134-142.

60. Wen F, Chen C, Wu D, Li H. Polypoidal choroidal vasculopathy in elderly Chinese patients. Graefes Arch Clin Exp Ophthalmol. 2004;242: 625-629.

61. Liu Y, Wen F, Huang S, et al. Subtype lesions of neovascular agerelated macular degeneration in Chinese patients. Graefes Arch Clin Exp Ophthalmol. 2007;245:1441-1445.

62. Ladas ID, Rouvas AA, Moschos MM, Synodinos EE, Karagiannis DA, Koutsandrea CN. Polypoidal choroidal vasculopathy and exudative agerelated macular degeneration in Greek population. Eye (Lond). 2004; 18:455-459.

63. Lafaut BA, Leys AM, Snyers B, et al. Polypoidal choroidal vasculopathy in Caucasians. Graefes Arch Clin Exp Ophthalmol. 2000;238: $752-759$.

64. Chang TS, Hay D, Courtright P. Age-related macular degeneration in Chinese-Canadians. Can J Ophthalmol. 1999;34:266-271.

65. Bird AC. The Bowman lecture. Towards an understanding of age-related macular disease. Eye (Lond). 2003;17:457-466.

66. Immonen I, Seitsonen S, Tommila P, et al. Vascular endothelial growth factor gene variation in age-related macular degeneration. Ophthalmology. 2010;117:103-108.

67. Imai D, Mori $\mathrm{K}$, Horie-Inoue $\mathrm{K}$, et al. CFH, VEGF, and PEDF genptypes and the response to intravitreous injection of bevacizumab for the treatment of age-related macular degeneration. J Ocul Biol Dis Infor. 2010;3:53-59.

68. Nischler C, Oberkofler H, Ortner C, et al. Complement factor H $\mathrm{Y} 402 \mathrm{H}$ gene polymorphism and response to intravitreal bevacizumab in exudative age-related macular degeneration. Acta Ophthalmol. 2011; 89:e344-e349.

69. Parmeggiani F, Costagliola C, Gemmati D, et al. Predictive role of coagulation-balance gene polymorphisms in the efficacy of photodynamic therapy with verteporfin for classic choroidal neovascularization secondary to age-related macular degeneration. Pharmacogenet Genomics. 2007;17:1039-1046.

70. Parmeggiani F, Costagliola C, Gemmati D, et al. Coagulation gene predictors of photodynamic therapy for occult choroidal neovascularization in age-related macular degeneration. Invest Ophthalmol Vis Sci. 2008;49:3100-3106.

71. Theodossiadis GP, Panagiotidis D, Georgalas IG, et al. Retinal hemorrhage after photodynamic therapy in patients with subfoveal choroidal neovascularizations caused by age-related macular degeneration. Graefes Arch Clin Exp Ophthalmol. 2003;241:13-18.
Clinical Ophthalmology

\section{Publish your work in this journal}

Clinical Ophthalmology is an international, peer-reviewed journal covering all subspecialties within ophthalmology. Key topics include: Optometry; Visual science; Pharmacology and drug therapy in eye diseases; Basic Sciences; Primary and Secondary eye care; Patient Safety and Quality of Care Improvements. This journal is indexed on Submit your manuscript here: http://www.dovepress.com/clinical-ophthalmology-journal

\section{Dovepress}

PubMed Central and CAS, and is the official journal of The Society of Clinical Ophthalmology (SCO). The manuscript management system is completely online and includes a very quick and fair peer-review system, which is all easy to use. Visit http://www.dovepress.com/ testimonials.php to read real quotes from published authors. 